\title{
Hair follicle discrimination dysfunction in multiple sclerosis patients
}

\author{
RICHARD J SCHNEIDER, RONALD BURKE \\ From the Laboratory of Neuroscience, Maryland Institute for Emergency Medical Service Systems, Baltimore, \\ Maryland, USA
}

SUMMARY A method was developed of assessing somatosensory deficits quantitatively using hair follicle displacement as a stimulus within a psychophysical signal detection task paradigm. Multiple sclerosis patients with and without somatosensory disturbances could be differentiated and compared with normal subjects. This method may distinguish patients with somatosensory dysfunction, and dorsal funiculus neuropathology may underlie this distinction.

Concern with the difficulty of assessing sensory perception is common to physiology, psychology and neurology. However, the outcome of studies of sensory function in these separate but related sciences have seldom been brought together. Advances in the neurophysiology of single cells and fibres in the cutaneous sensory system of the body (somatosensory electrophysiology) and the psychology of stimulus-response relationships (psychophysics) may provide answers to questions concerning the detection of somatosensory dysfunction.

The general problem is how to identify and measure differences in sensory acuity relating to physiological organisation (for example, somatosensory pathway anatomy and function), psychophysical factors (for example, the cognitive significance of responses), and neurological pathology relating to disease or injury. For example, both in man and monkeys, researchers have had difficulty in determining deficits ensuing from lesions to selected pathways, such as, the dorsal funiculus. ${ }^{1-10}$ Although some researchers were able to show sustained sensory deficits in monkeys, ${ }^{11-13}$ a precise, quantifiable method of demonstrating the traditionally taught pattern of dysfunction eluded them. Moreover, the attempt to show deficits with simple passively applied stimuli led to failures which stimulated speculation on differing roles for the dorsal funiculus pathway ${ }^{14-16}$ and to explanations involving redundancy of spinal sensory pathways. ${ }^{17}$ Meanwhile, other evidence was coming to light which

Address for reprint requests: Dr RJ Schneider, Laboratory of Neuropsychology, Building 9, Room IN107, National Institute of Mental Health, Bethesda, MD 20205, USA.

Received 21 June 1981 and in revised form 13 November 1981 Accepted 12 December 1981 could account for these failures and which suggested further investigation that might demonstrate these sensory losses. ${ }^{18-20}$ Thus, we showed that information from hair follicle stimuli was transmitted to the primary somatosensory cortex uniquely via the dorsal funiculus in Macaca mulatta monkeys. ${ }^{192021}$ These studies on the monkey suggested that neurological deficits related to dorsal column dysfunction would be detected especially well by tests of hair follicle displacement discrimination. Further, psychophysical methods had evolved which enabled us to control for misleading results deriving from psychophysical factors (for example response bias) in gross neurological examination. ${ }^{21}{ }^{23}$ This study combined our insights on the transmission of hair follicle displacement sensation in monkeys with psychophysical methods for analysis of sensory acuity. The purpose of this present study has been to create an objective, quantifiable and sensitive means of detecting somatosensory deficits in patients with spinal cord neuropathology. We have investigated patients with sensory pathology caused by the demyelination or plaque formation associated with multiple sclerosis.

\section{Methods}

Multiple sclerosis patients were solicited from a group referred to the Department of Hyperbaric Medicine at the Maryland Institute for Emergency Medical Services Systems for experimental treatment with hyperbaric oxygen. All had been diagnosed as having multiple sclerosis by at least two physicians. Their sensory symptoms were evaluated from medical records, from interviews and from a neurological examination prior to the testing sessions. Five patients were selected for study. Three of them-males 
aged 35,38 and 48-had sensory symptoms which had not resolved at the time of the study. They all complained of sensory loss or paraesthesiae-numbness, tingling, temperature sensations-both transiently in the past and at the time of testing. All could walk, but they had difficulty with balance, motor control and coordination of the legs. Two-a male aged 39 and a female aged 28-had no sensory symptoms at the time of the study. The female patient had experienced sensory paraesthesiae in the past which had resolved. The male had never complained of sensory disturbances, but had a great deal of motor difficulty. The four normal control subjects were drawn from the population of the Institute's employees; they were two females and two males aged 28, 32, 26 and 34 years, respectively. Female subjects refrained from shaving their legs for two weeks prior to testing.

By means of electromechanical and logic circuitry a sequence of events constituting a psychophysical yes/no discrimination task was presented to subjects in a manner consistent with signal detection theory (TSD). ${ }^{21}$ The procedure and the associated series of events as applied by us are described below. These events included an alerting light, a mechnical hair displacement stimulus and a feedback light. The lights were standard green and white 7.5 watt bulbs. The mechanical stimulus was delivered by a galvanometer (MFE, model R-4-154) which oscillated at a frequency of $10 \mathrm{~Hz}$. A $1.5 \mathrm{~mm}$ long brass rod was attached at a right angle to the longitudinal axis of the galvanometer shaft (fig). This rod contacted and displaced hair follicles $1 \mathrm{~mm}$ above the skin surface of the subject's leg. Hair follicle displacement was at either $9.45 \mathrm{~mm}\left(\mathrm{~S}^{+}\right)$or $6.20 \mathrm{~mm}$ $\left(\mathrm{S}^{-}\right)$measured at the tip of the oscillating rod. Thus, the difference in hair displacement to be discriminated at the tip of the rod was $3.25 \mathrm{~mm}$. A blind prevented the subject from viewing the stimulus delivery. A trough restrained leg movements while comfortably supporting the leg of the seated subject (fig). A holder for the galvanometer permitted omnidirectional placement while damping vibration; it avoided cues being transmitted to the subject via the leg restraint trough.

The sequence of events was as follows. The central programming equipment initiated a discrete trial every eight seconds, the start of the trial being denoted by a green lamp. Two seconds later, either of the two amplitudes of hair displacement was presented with equal probability $\left(\mathrm{p}\left(\mathrm{S}^{+}\right)=\mathrm{p}\left(\mathrm{S}^{-}\right)=0.5\right)$ in a quasirandom sequence. The subject identified which of the two stimuli was being presented either by pressing or refraining from pressing a

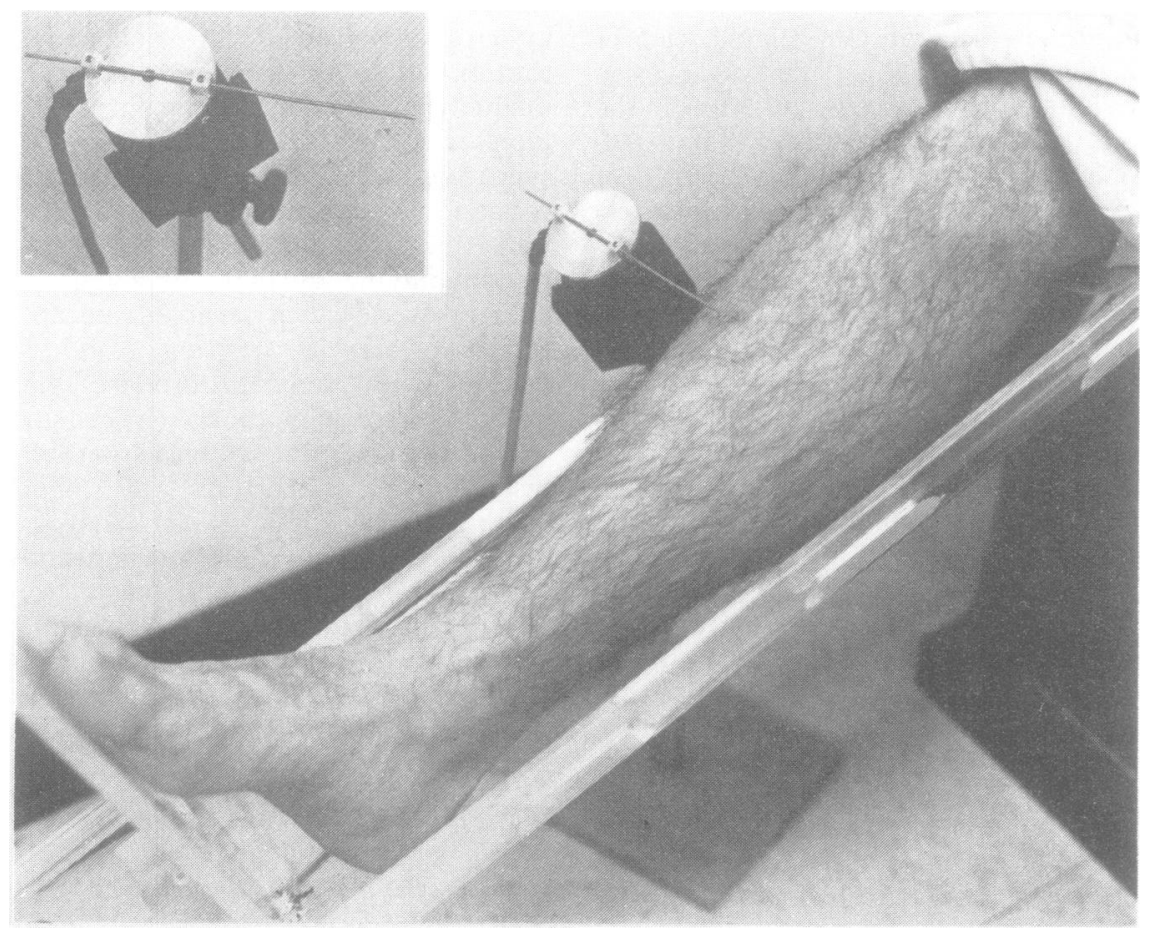

Figure Hair follicle displacement stimulus arrangement. The subject sits with his or her leg resting in an adjustable, plexiglass trough. The hair follicle stimulator is held by a vibration damping, omnidirectional supporting stand. The stimulator oscillates a brass rod which displaces hair follicles both rostrally and caudally (depending on the phase of the oscillation) during each stimulus presentation. The rod oscillates along the long axis of the leg. Holes in the trough permit access to medial, lateral and posterior dermatomes as well as anterior shown here being stimulated. Inset: Close-up of stimulator and holder. 
hand held button. A response when $\mathrm{S}^{+}$was presented was defined as a correct identification. In all cases a stimulus was presented for a maximum of 2 seconds. If a button press response did not occur during this observation interval, the subject was considered to have refrained from pressing. The alerting lamp and the hair follicle displacement stimulus (either $\mathrm{S}^{+}$or $\mathrm{S}^{-}$) were extinguished immediately following the button press response or the elapse of the two second observation interval. If a correct identification was recorded, which could either be pressing the button when $\mathrm{S}^{+}$was presented or refraining from pressing the button when $S^{-}$was presented, the white lamp was illuminated for 0.5 seconds. Incorrect identification did not cause this (feedback) lamp to be illuminated. Thus, the subject was presented with a series of discrete trial successive discriminations. He identified which stimulus had been presented during each discrete trial by either pressing or not pressing a push button. Correct identifications were followed by the illumination of a feedback lamp and incorrect identifications were not. This procedure is analogous to a yes/no signal detection theory paradigm where the alerting interval is two seconds and the observation and response intervals are concurrent and two seconds in length.

The purpose and methods of the experiment were explained to the subject. The operation of the logic equipment and the sequence of stimulus events was demonstrated and explained. The subject's right leg was restrained in an elevated position (in our sample the sensory disturbance had always been worse on this side) and the area to be stimulated was exposed. The galvanometer was positioned and the subject began a series of practice trials. During initial testing of a subject, practice might involve verbal coaching by the experimenter or allowing the subject to view the stimuli as they were presented. With repeated testing sessions the subject gained understanding of the experiment and practice might involve as few as twenty trials. In all cases practice was continued at least until the subject expressed the desire to proceed to the actual experimental task. The results of practice were discarded. During testing and data collection the galvanometer was screened from the subject's view as men- tioned above, and the experimenter was not in the room with the subject. Testing continued until a series of 180 discrete trials had been presented. Each subject was tested repeatedly, various numbers of times at irregular intervals.

The results of the experiment were analysed in accordance with signal detection theory. Research has demonstrated the reduced variability inherent in dependent variables based on the assumptions of signal detection theory. ${ }^{24}$ Preliminary research in this laboratory has confirmed this result ${ }^{25-27}$ and demonstrated the independence of the signal detection theory sensitivity measure $\mathrm{d}^{\prime}$ and the associated criterion or bias measure beta $(\beta)$. These results recommend $d^{\prime}$ as a superior dependent variable to employ in experiments of this type. ${ }^{*}$

\section{Results}

Gross neurological sensory examination of the legs of the multiple sclerosis patients revealed no obvious deficits in two-point discrimination, vibratory sensation (tuning fork at $128 \mathrm{~Hz}$ ), light touch sensation with cotton wool, pin-prick sensation, thermal sensation, proprioception (toe movement) or, in particular, hair displacement sensation produced by bending individual hairs with forceps. After subjective testing, these patients were tested on the objective, psychophysical paradigm.

Following the series of 180 discrete trials, $\mathrm{d}^{\prime}$ was computed for each subject. For analytic purposes, mean $\mathrm{d}^{\prime}\left(\mathbf{M d}^{\prime}\right)$ was computed for each subject over all blocks of discrete trials presented to that subject. Each subject's $\mathrm{Md}^{\prime}$ was then based on $\mathrm{n} \times 180$ discrete trials. The figures in the table present $\mathbf{M d}^{\prime}$

\begin{abstract}
*As applied here, $d^{\prime}$ is a quantitative measure of the capacity of the somatosensory system to distinguish one stimulus from another. Subjects who distinguish two given stimuli more accurately will have a higher $d^{\prime}$ than those who are less accurate. If somatosensory capacity is diminished, stimuli are less accurately distinguished and $d^{\prime}$ is reduced.
\end{abstract}

Table

\begin{tabular}{|c|c|c|c|c|c|}
\hline $\begin{array}{l}\text { Normal subjects } \\
\text { Subject } \\
\text { Sex } \\
\text { Md' } \\
\text { SD } \\
\mathrm{N}^{\prime}\end{array}$ & $\begin{array}{l}1 \\
\text { male } \\
2 \cdot 205 \\
0 \cdot 578 \\
13\end{array}$ & $\begin{array}{l}2 \\
\text { male } \\
2 \cdot 567 \\
0 \cdot 448 \\
3\end{array}$ & $\begin{array}{l}3 \\
\text { female } \\
2.345 \\
0.793 \\
4\end{array}$ & $\begin{array}{l}4 \\
\text { female } \\
2 \cdot 037 \\
0.254 \\
3\end{array}$ & $\begin{array}{l}\text { All sutjects } \\
2 \cdot 289 \\
0 \cdot 224 \\
23\end{array}$ \\
\hline $\begin{array}{l}\text { Multiple sclerosis } \\
\text { Subject } \\
\text { Sex } \\
\text { Md' } \\
\text { SD } \\
\mathrm{N}^{\prime}\end{array}$ & $\begin{array}{c}\text { nts (with } \\
1 \\
\text { male } \\
1.788 \\
0.478 \\
13\end{array}$ & $\begin{array}{l}\text { mptoms) } \\
2 \\
\text { male } \\
1 \cdot 333 \\
0.700 \\
12\end{array}$ & $\begin{array}{l}3 \\
\text { male } \\
1.414 \\
0.357 \\
4\end{array}$ & 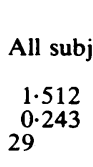 & \\
\hline $\begin{array}{l}\text { Multiple sclerosis } \\
\text { Subject } \\
\text { Sex } \\
\text { Md' } \\
\text { SD } \\
\mathbf{N}^{1}\end{array}$ & $\begin{array}{l}\text { nts (witho } \\
1 \\
\text { female } \\
2.550 \\
0.997 \\
5\end{array}$ & $\begin{array}{l}\text { symptom } \\
2 \\
\text { male } \\
2.343 \\
0.668 \\
4\end{array}$ & $\begin{array}{l}\text { All sub } \\
2 \cdot 447 \\
0 \cdot 146 \\
9\end{array}$ & & \\
\hline
\end{tabular}

$\mathrm{N}^{1}$ represents the number of times a subject was presented a block of trials where each block of trials consisted of 180 discrete trials. 
and the standard deviation of $d^{\prime}$ (SD) for each subject and for each group of subjects.

The group differentiation, normal, multiple sclerosis with sensory symptoms and multiple sclerosis without sensory symptoms, was based on the assumption that a diagnosis of multiple sclerosis was not fundamental to sensory dysfunction. Rather, a history of sensory dysfunction in somatosensation (for example, paraesthesiae) was indicative, and therefore no difference in $\mathrm{Md}^{\prime}$ was to be expected between the normal and multiple sclerosis without sensory symptom groups. The validity of this assumption was evaluated by comparing $\mathrm{Md}^{\prime}$ between these latter two groups using the Sheffe method. The resulting difference was found to be insignificant (difference $=0 \cdot 158$, degrees of freedom $=2 / 6$, probability $<$ non-significant).

Based on the equivalence of the normal and multiple sclerosis without sensory symptoms groups, these subjects were combined to form a single group $\left(\mathrm{Md}^{\prime}=2 \cdot 341, \mathrm{SD}=0 \cdot 185, \mathrm{n}=6\right)$. A confidence interval was then computed to estimate the limits within which $\mathrm{Md}^{\prime}$ for this combined group could be expected to fall. The result of this computation gave us the interval $\mathrm{P}(2.092<\mathrm{u}<2.590)=0.999$. Comparison of $\mathrm{Md}^{\prime}$ for the multiple sclerosis with sensory symptoms group, $\mathrm{Md}^{\prime}=1 \cdot 512$, to the range of this confidence interval strongly suggests that these $d^{\prime}$ values were sampled from different populations. In other words, the score of the group of multiple sclerosis patients with sensory symptoms like paraesthesiae in the legs, by being comparatively low in sensitivity, falls outside the range of scores which can be expected for the sensory symptom free, combined group. The magnitude of the effect of the experimental differentiation multiple sclerosis patient versus normal subject accounts for $80 \%$ of the sample variance and $70 \%$ of the population variance.

\section{Discussion}

Our goal was to determine whether we could objectively evaluate sensory dysfunction in multiple sclerosis patients with psychophysical methods, analysing the data by signal detection theory. The results showed that this was so. However, we acknowledge that the small sample size and unequal number of subjects (cell frequencies) in each group limit the generality of our analysis. But the homogeneity of variance and the large number of discrete trials presented to each subject suggest that these data are highly reliable. The greater the number of trials presented to a subject, the smaller the error of estimating $d^{\prime}$ for that subject. ${ }^{21}$
Concerning the magnitude of the effect, one guide to it is the proportion of variance accounted for by the experimental differentiation. When that proportion is about $30 \%$, it is conventionally considered a small to medium effect size. In the present case, the magnitude of the effect accounted for more than $70 \%$ of the variance. An effect this size would be termed strong. If we compare the two groups without sensory symptoms-normal subjects and those with multiple sclerosis - to the multiple sclerosis group with sensory symptoms, we have samples of two populations-one without sensory symptoms, the other with them: these were estimated to differ by 3.5 standard deviation units. An effect this strong, the repeated measures design and the relatively small variability in the data should leave little doubt that a valid difference between these two samples of subjects was demonstrated.

In the absence of histologically confirmed pathology, we are assuming that a history of sensory loss and paraesthesiae indicate sensory tract neuropathology. This may or may not be so, but the normal scores of the multiple sclerosis group without sensory symptoms suggest that there is nothing intrinsic about multiple sclerosis which causes lower scores. Recent studies ${ }^{28}$ in the monkey indicate that paraesthesiae may result from anterolateral white matter damage without involvement of other spinal afferent pathways like the dorsal funiculus. Nevertheless, our patients had no gross diminution of sensation to pin-prick, warmth or cold, which are all sensations which require an intact spinothalamic tract. This may indicate the difficulty in comparing sensations inferred in animals with sensations in humans. On the other hand, it might be that a high resolution examination of the kinds of sensations in humans dependent on conduction in the spinothalamic tract with proper stimuli and psychophysical methods like the ones used here would uncover a sensory deficit not apparent on gross examination. Whatever the case, we believe the assumption of sensory tract neuropathology is valid.

The origin of this study was the observation that the hair follicle projection to the primary somatosensory cortex in Macaca mulatta was completely eliminated by a dorsal funicular tractotomy. Our later studies with behaving Macaca mulatta monkeys showed that sensory loss on a hair follicle discrimination task indicated dorsal funiculus damage. ${ }^{25-27}$ In humans we have found such results are independent of hair density, sex, age and other non-nervous factors. In humans, we cannot know the precise pathways involved nor the extent of contribution of each. Multiple sclerosis, of course, presents disseminated neuropathology. We have no reason to believe, however, that the pathways are 
markedly different in humans from those in monkeys. The development of the dorsal funiculus coincided with the evolution of mammals. ${ }^{29}$ The appearance of body hair instead of reptilian scales is a notable morphological change in mammals. It is reasonable to assume that evolving spinal sensory pathiways would transmit information from the newly evolved hair follicles. In monkeys and man, the dorsal funiculus is the dominant, recently developed, spinal sensory pathway. Consequently, experimental results on monkeys may be more pertinent to the human nervous system than those on other animals.

We believe that failures to document deficits in man and monkeys following dorsal funicular lesions have resulted from choices of stimuli transmitted redundantly by several pathways, ${ }^{17}$ from not taking into account such processes as fibre sorting, ${ }^{182030}$ and from methodological weaknesses in the manner of applying sensory testing or psychophysics to animals. ${ }^{31-33}$ Some researchers have chosen stimuli which are related to neurological tests for somatosensation. Directional, moving touch would seem to mimic the components of graphaesthesia, for example. By the use of such a stimulus, a sustained deficit following dorsal funiculus tractotomy in monkeys has been found. ${ }^{12}$ Others have chosen stereognostic type tasks wherein the animal seems to require the dorsal funiculus to make an accurate discrimination." Our earlier electrophysiological results ${ }^{1922}$ show that several stimulus submodality complexes, that is, hair follicle displacement, distal glabrous skin touch and distal proprioception, are transmitted to the primary somatosensory cortex in Macaca mulatta uniquely via the dorsal funiculus. Distal proprioception is already widely used by neurologists to evaluate dorsal funiculus dysfunction. We chose another of these types of passive stimulation to assess suspected somatosensory dysfunction. When this stimulation is combined with an appropriate sensitive methodological approach to evaluating sensation taken from psychophysics, ${ }^{21}{ }^{23}$ we are able to quantify sensory deficits in humans. It is easier to quantify our task than it would be for graphaesthetic or stereognostic ones, and such quantification clearly shows that passive losses coexist with active ones. We believe psychophysical testing with the appropriate stimuli allows us to work out the location (tract) and the extent of a spinal lesion. As such, it may be developed into a powerful tool for neurologists.

We thank Dr RA Cowley for his support of this study and Dr Roy Myers for his assistance in providing a population of multiple sclerosis patients. Sup- ported by grant number RG-1207-A-1 from the National Multiple Sclerosis Society.

\section{References}

' Rabiner AM, Browder EJ. Concerning conduction of touch and deep sensibilities through the spinal cord. Trans Am Neurol Ass 1948;73:137.

${ }^{2}$ Mettler FA, Liss H. Functional recovery in primates after large subtotal spinal cord lesions. $J$ Neuropath Exp Neurol 1959;18:509-16.

${ }^{3}$ Cristiansen J. Neurological observations of macaques with spinal cord lesions. Anat Rec 1966;154:330.

4 Cook AW, Browder EJ. Functions of posterior columns in man. Arch Neurol 1966;12:72-9.

${ }^{5}$ Levitt M, Schwartzman R. Spinal sensory tracts and two-point tactile sensitivity. Anat $\operatorname{Rec} 1966 ; 154: 436$.

- Vierck CJ Jr. Spinal pathways mediating limb position sense. Anat Rec 1966;154:436.

${ }^{7}$ Eidelberg E, Kreinick CJ, Langeschied C. On the possible functional role of afferent pathways in skin sensation. Exp Neurol 1975;47:419-32.

${ }^{8}$ Eidelberg E, Rick C. Lack of effect of partial spinal cord sections upon thermal discrimination in the monkey. Appl Neurophysiol 1975;38:145-52.

${ }^{9}$ Schwartzman RJ, Bogdonoff MD. Behavioral and anatomical analysis of vibration sensitivity. Exp Neurol 1968;20:43-51.

${ }^{10}$ Schwartzman RJ, Bogdonoff MD. Proprioception and vibration sensibility discrimination in the absence of the posterior columns. Arch Neurol 1969;20:349-53.

"Azulay A, Schwartz AS. The role of the dorsal funiculus of the primate in tactile discrimination. Exp Neurol 1975;46:315-32.

12 Vierck CJ Jr. Tactile movement detection and discrimination following dorsal column lesions in monkeys. Exp Brain Res 1974;20:331-46.

${ }^{13}$ Vierck CJ Jr. Proprioceptive deficits after dorsal column lesions in monkey. In: Kornhuber $\mathrm{HH}$, ed. The Somatosensory System. Stuttgart: Georg Thieme Verlag, 1975:310-7.

${ }^{14}$ Semmes J. Protopathic and epicritic sensation: A reappraisal. In: Benton AL, ed. Contributions to Clinical Neuropsychology. Chicago: Aldine, 1969:142-71.

15 Wall PD. The sensory and motor role of impulses traveling in the dorsal columns towards cerebral cortex. Brain 1970;93:505-24.

${ }^{16}$ Wall PD, Noordenbos W. Sensory functions which remain in man after complete transection of dorsal columns. Brain 1977;100:641-53.

${ }^{17}$ Eidelberg E, Woodbury C. Apparent redundancy in the somatosensory system in monkeys. Exp Neurol 1972;37:573-81.

18 Whitsel BL, Petruocelli LM, Sapiro G, Ha H. Fiber sorting in the fasciculus gracilis of squirrel monkeys. Exp Neurol 1970;29:227-42.

${ }^{19}$ Schneider RJ. The effects of lesions of the posterior funiculus of Macaca mulatta. Ph.D. Dissertation, Univ Pittsburgh, 1972.

${ }^{20}$ Dreyer DA, Schneider RJ, Metz C, Whitsel BL. Differential contributions of spinal pathways to the body 
representation in the postcentral gyrus. $J$ Neurophysiol 1974;37:119-45.

${ }^{21}$ Green DM, Swets JA. Signal Detection Theory and Psychophysics. New York: Krieger, 1974.

${ }^{22}$ Schneider RJ, Kulics AT, Ducker TB. Proprioceptive pathways of the spinal cord. J Neurol Neurosurg Psychiatry 1977;40:417-33.

${ }^{23}$ Egan JP. Signal Detection and ROC Analysis. New York: Academic Press, 1975.

${ }^{24}$ Pollack I, Hsieh RH. Sampling variability of the area under the ROC curve and of d'. Psych Bull 1969;71:161-73.

${ }^{25}$ Schneider RJ, Burke RF. Detection of sub-clinical spinal tract sensory dysfunction. Soc Neurosci Abstr 1979;5:729.

${ }^{26}$ Schneider RJ, Burke RF. Detection of sensory spinal tract dysfunction with signal detection theory. Soc Neurosci Abstr 1980;6:727.

${ }^{27}$ Schneider RJ, Burke RF. Psychophysical evaluation of somatosensory impairment implicating dorsal (column) funiculus involvement. Soc Neurosci Abstr 1981;7:612.
${ }^{28}$ Levitt M, Levitt JH. The deafferentation syndrome in monkeys: dysesthesias of spinal origin. Pain 1981;10:129-47.

${ }^{29}$ Ariëns-Kappers CU, Huber GHC, Crosby EC. The Comparative Anatomy of the Nervous System of the Vertebrates Including Man. New York: Macmillan, 1936.

${ }^{30}$ Horch KW, Burgess PR, Whitehorn D. Ascending collaterals of cutaneous neurons in the fasciculus gracilis of the cat. Brain Res 1976;117:1-17.

${ }^{31}$ Blough DS. The study of animal sensory processes by operant methods. In: Honig WK, ed. Operant Behavior: Areas of Research and Application. New York: Appleton-Century-Crofts, 1966:345-79.

${ }^{32}$ Stebbins WC. Principles of animal psychophysics. In: Stebbins WC, ed. Animal Psychophysics: The Design and Conduct of Sensory Experiments. New York: Appleton-Century-Crofts, 1970:1-19.

${ }^{33}$ Blough DS, Blough P. Animal psychophysics. In: Honig WK and Staddon JER, eds. Handbook of Operant Behavior. New Jersey: Prentice Hall, 1977:514-39. 